\title{
Recruitment methods for screening programmes: trial of an improved method within a regional osteoporosis study
}

\author{
D J Torgerson, M J Garton, C Donaldson, \\ I T Russell, D M Reid
}

Health Economics Research Unit, University of Aberdeen, Polwarth Building, Foresterhill, Aberdeen AB9 2ZD

D J Torgerson, research fellow

C Donaldson, deputy director

Department of

Rheumatology, City

Hospital, Aberdeen AB9

8 AU

M J Garton, clinical research fellow

D M Reid, consultant

rheumatologist

Health Services Research Unit, University of Aberdeen, Polwarth Building, Foresterhill, Aberdeen AB9 2ZD

I T Russell, director

Correspondence to:

Mr Torgerson.

BM7 1993;307:99
Non-attendance for health care is a common and expensive problem..$^{1-3}$ Ideally, a recruitment method should combine high compliance (the proportion of invited patients who attend) with a high attendance rate (the proportion of appointment slots used or slot coverage rate). We have suggested that a recruitment method combining open invitations with confirmable reminders achieves this. ${ }^{3}$ We compared this suggestion with a standard appointment method $^{4}$ within a regional programme for osteoporosis.

\section{Methods and results}

Methods were similar to those of our first study. ${ }^{3}$ Women were randomly recruited to screening by one of two methods.

Standard method-The initial letter offered a specific (fixed) appointment. The recipient was asked to contact the screening unit only if she wished to change or cancel her appointment. Reminder letters were open, asking non-respondents to contact the unit to make an appointment.

Improved method - The initial letter was open, asking the recipient to contact the screening unit to make an appointment. Reminder letters asked non-respondents to confirm a specified appointment or lose it.

The table shows the results. The difference in final

Compliance and slot coverage rates * by method of recruitment

\begin{tabular}{|c|c|c|}
\hline & Standard method & Improved method \\
\hline \multicolumn{3}{|c|}{ Before reminders } \\
\hline $\begin{array}{l}\text { No of women invited (slots } \\
\text { available) }\end{array}$ & 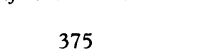 & 373 \\
\hline No $(\%)$ of slots allocated before & & \\
\hline reminders $\dagger$ & $365(97)$ & $206(55)$ \\
\hline $95 \%$ confidence interval $(\%)$ & 95 to 99 & 50 to 60 \\
\hline \multicolumn{3}{|l|}{ Initial compliance: } \\
\hline $\begin{array}{l}\text { No (\%) of women invited } \\
\text { who attended }\end{array}$ & $292(78)$ & $199(53)$ \\
\hline $95 \%$ Confidence interval (\%) & 74 to 82 & 48 to 58 \\
\hline No $(\%)$ of wasted slots & $73(19)$ & $7(2)$ \\
\hline Initial slot coverage rate $(\%)$ & 80 & 97 \\
\hline $95 \%$ Confidence interval $(\%)$ & $\begin{array}{l}76 \text { to } 84 \\
\text { After reminders }\end{array}$ & 93 to 99 \\
\hline \multicolumn{3}{|l|}{ No (\%) of slots available } \\
\hline for reuse & $10(375-365)(3)$ & $167(373-206)(45)$ \\
\hline $\begin{array}{l}\text { No }(\%) \text { of reminders issued } \neq \\
\text { No }(\%) \text { of slots allocated to }\end{array}$ & $73(365-292)(19)$ & $167(373-206)(45)$ \\
\hline reminders & $10(14)$ & $89(53)$ \\
\hline \multicolumn{3}{|l|}{ No $(\%)$ scanned after } \\
\hline $\begin{array}{l}\text { reminders } \\
95 \% \text { Confidence interval }\end{array}$ & $7(10)$ & $87(52)$ \\
\hline $95 \%$ Confidence interval & 4 to 19 & 44 to 60 \\
\hline No (\%) of wasted slots & $\begin{array}{l}3(10-7)(1) \\
\text { Results }\end{array}$ & $2(89-87)(1)$ \\
\hline \multicolumn{3}{|l|}{$\begin{array}{l}\text { Final compliance: } \\
\text { No }(\%) \text { of women invited }\end{array}$} \\
\hline who attended & $299(80)$ & $286(77)$ \\
\hline $95 \%$ Confidence interval $(\%)$ & 76 to 84 & 72 to 81 \\
\hline Final slot coverage rate $(\%) \|$ & 80 & 98 \\
\hline $95 \%$ Confidence interval (\%) & 76 to 84 & 93 to 99 \\
\hline
\end{tabular}

^Number of slots used as a percentage of the number of slots available. tFor the standard method number of invitations issued minus number of cancelled appointments; for the improved method number of women contacting unit to confirm or make an appointment.

†Reminders were sent only to women who did not respond; thus for the standard method women were sent reminders if they did not cancel and did not keep their appointment; for the improved method only women who did not make an appointment received reminders.

TTotal number of available slots minus total number of wasted slots as a peral number compliance between methods $(3 \%)$ was not significant (95\% confidence interval for the difference $-3 \%$ to $9 \%$ ). However, the improved method achieved a slot coverage rate $18 \%$ higher than the standard method $(12.7 \%$ to $21 \cdot 7 \%)$.

The opportunity cost of each method was calculated by multiplying the fixed slot cost $(£ 19.50$ and $£ 19.90$ for standard and improved methods respectively) by the annual number of slots left unused. The final slot coverage rate of the standard method was $80 \%$ (table); in a programme with 2250 screening slots available annually 456 slots (20\%) would be wasted, costing $£ 8890$. But as the improved method has a slot coverage rate of $98 \%$ only $54(2 \%)$ would be wasted each year at a cost of $£ 1070$. Thus the advantage of using the improved method is that 402 more women can have a screening test, equivalent to a financial benefit of $£ 7820$.

Three extra financial costs are incurred with the improved method. Firstly, more secretarial time is needed to answer the telephone, reflected in a fixed slot cost of $£ 19.90$ compared with $£ 19.50$ for the standard method; thus the improved method would result in additional annual secretarial costs of $£ 900(2250 \times$ $£ 0 \cdot 40)$. Secondly, the improved method needs more reminders ( $45 \%, 167$ out of 373 women) than the standard method $(19 \%, 73$ out of 375 women); this would result in an extra annual reminder cost of $£ 164$ $(0.26 \times 2250 \times £ 0 \cdot 28)$. Thirdly, more open invitations would need to be sent than the number of slots available because the improved method would otherwise leave $21 \%$ of slots unused (calculated by taking the number of slots allocated to reminders from the number of slots available for reuse) (table); 859 extra open invitations would have to be issued at an annual cost of $£ 240(2250 \times 0.21 / 0.55 \times £ 0 \cdot 28)$. Thus there would be a net administrative cost of $£ 1300$ to offset the benefit of $£ 7820$

\section{Comment}

Non-attendance has important resource implications for screening programmes. Response rates to breast screening can be as low as $50 \%$, resulting in substantial wasting of resources. ${ }^{5}$ However, our results show that a recruitment method combining an open invitation with a confirmable reminder achieves high compliance at lower cost. We also tested a recruitment method that combined an initial confirmable invitation followed by an open reminder. This combination, however, resulted in worse compliance and greater wasting of resources than occurred with the standard method.

By combining open invitations with confirmable reminders screening programmes could be offered to larger populations, thereby detecting more disease within current resources.

DT and MG are funded by the Wolfson Foundation. CD and IR are supported by the Chief Scientist Office of the Home and Health Department of the Scottish Office. David Reid thanks the Arthritis and Rheumatism Council for continued support. The views expressed are not necessarily those of the funding bodies.

1 McGlade KJ, Bradley T, Murphy GJJ, Lundy GPP. Referrals to hospital by general practitioners: a study of compliance of communication. $B M 7$ 1988;297:1246-8.

2 Andrews R, Morgan JD, Addy DP, McNeish AS. Understanding nonattendance in outpatient paediatric clinics. Arch Dis Child 1989;65:192-5.

3 Garton MJ, Torgerson DJ, Donaldson C, Russell IT, Reid DM. Recruitment methods for screening programmes: trial of a new method within a regional osteoporosis study. BMf 1992;305:82-4.

4 Department of Health Advisory Committee. Consolidated guidance on breast cancer screening. Oxford: Screening Publications, 1990:7.

5 McEwen J, King E, Bickler G. Attendance and non-attendance for breast screening at the south east London breast screening service. BMf 1989;299: 104-6.

Accepted 11 May 1993) 